\title{
Clinical Pharmacology Of Endothelin Receptor Antagonists Used In The Treatment Of Pulmonary Arterial Hypertension
}

\author{
Marie-Camille Chaumais ${ }^{1,2,3}$, Christophe Guignabert ${ }^{2}$, Laurent Savale ${ }^{2,5}$, Xavier Jaïs ${ }^{2,5}$, \\ Athénaïs Boucly ${ }^{5}$, David Montani ${ }^{2,4,5}$, Gérald Simonneau ${ }^{2,4,5}$, Marc Humbert ${ }^{2,4,5}$, Olivier Sitbon ${ }^{2,4,5}$.
}

1. Univ. Paris-Sud, Faculté de Pharmacie, Châtenay Malabry, France

2. INSERM UMR_S 999, LabEx LERMIT, Centre Chirurgical Marie Lannelongue, Le Plessis-Robinson, France

3. AP-HP, Service de Pharmacie, Département Hospitalo-Universitaire (DHU) Thorax Innovation, Hôpital Antoine Béclère, Clamart, France

4. Univ. Paris-Sud, Faculté de Médecine, Le Kremlin-Bicêtre, France

5. AP-HP, Centre de Référence de l'Hypertension Pumonaire Sévère, Département HospitaloUniversitaire (DHU) Thorax Innovation, Service de Pneumologie et, Hôpital Bicêtre, Le KremlinBicêtre, France.

\section{Corresponding author:}

Olivier Sitbon, MD PhD

Service de Pneumologie et Soins Intensifs

Hôpital Universitaire de Bicêtre,

78, rue du Général Leclerc

94270 Le Kremlin-Bicêtre, France.

Tel: +33 (1) 145217972

Fax: +33 (1) 145217971

E-mail: olivier.sitbon@bct.aphp.fr 


\begin{abstract}
Pulmonary arterial hypertension (PAH) is a devastating life-threatening disorder characterized by elevated pulmonary vascular resistance leading to elevated pulmonary arterial pressures, right ventricular failure and ultimately death. Vascular endothelial cells mainly produce and secrete endothelin (ET-1) in vessels that lead to a potent and long-lasting vasoconstrictive effect in pulmonary arterial smooth muscle cells. Along with its strong vasoconstrictive action, ET-1 can promote smooth muscle cell proliferation. Thus, ET-1 blockers have attracted attention as an antihypertensive drug and the ET-1 signaling system has paved a new therapeutic avenue for the treatment of PAH. The present chapter outlines not only the current understanding of the pathogenic role played by ET-1 signaling systems in the pathogenesis of $\mathrm{PH}$, but also on the clinical pharmacology of endothelin receptor antagonists (ERA) used in the treatment of PAH.
\end{abstract}

Keywords: Pulmonary arterial hypertension; Endothelial dysfunction; Endothelin; Endothelin receptor antagonists. 


\section{Contents}

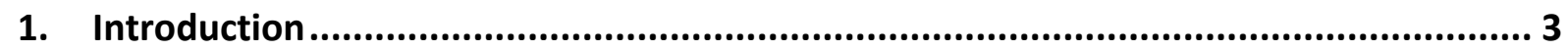

2. Pulmonary Endothelial Dysfunction in PAH .......................................................... 4

3. The endothelin (ET)-1 signaling system pathway in PAH ......................................... 4

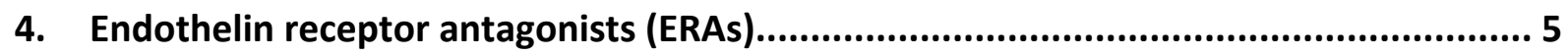

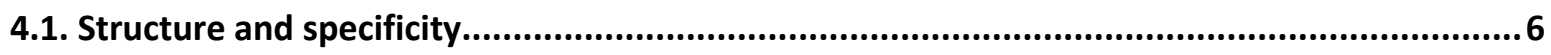

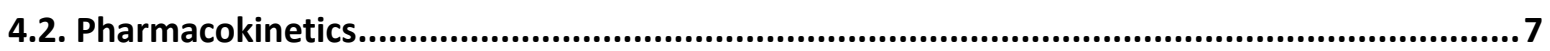

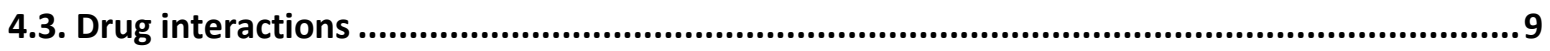

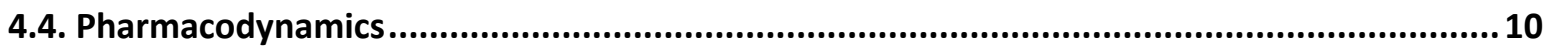

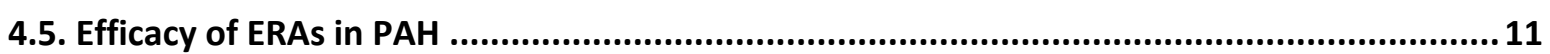

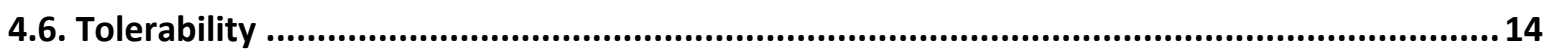

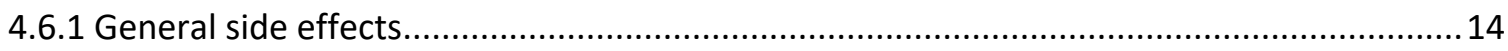

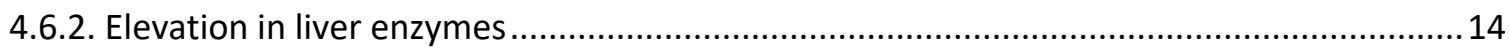

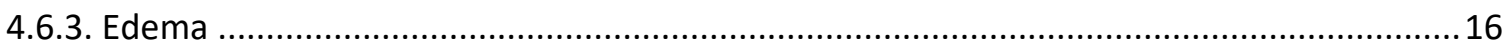

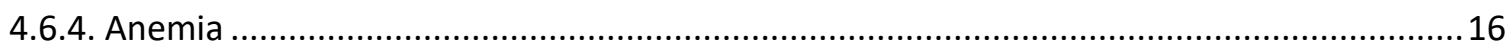

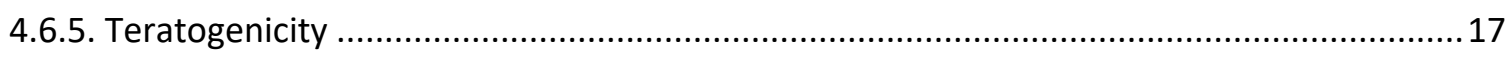

5. Place of ERAs in the treatment algorithm for PAH ......................................... 17

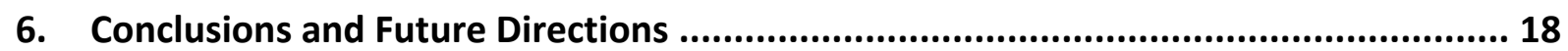

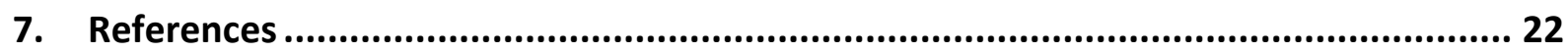

\section{Introduction}

Pulmonary arterial hypertension (PAH) is a rare condition characterized by severe remodeling of the small pulmonary arteries leading to chronic pre-capillary pulmonary hypertension (defined by a mean pulmonary artery pressure $>25 \mathrm{mmHg}$ with a mean pulmonary artery wedge pressure $<15 \mathrm{mmHg}$ ), right heart failure and ultimately death. Development of therapeutic agents that modulate the three main dysfunctional pathobiologic pathways (endothelin [ET-1], prostacyclin [PGI2], and nitric oxide [NO] have revolutionized our approach to the treatment of PAH and have changed the course of this devastating disease ${ }^{1}$. However, although the spectrum of therapeutic options for PAH has expanded in the last decade, available therapies remain essentially palliative. Since 2002, the dual endothelin receptor antagonist (ERA) bosentan is available for the management of PAH. Research on new ERA resulted in the development of two other drugs, ambrisentan and more recently macitentan. 


\section{Pulmonary endothelial dysfunction in PAH}

The various conditions that comprise PAH share a broadly similar pathobiology, leading to the establishment of a treatment-based classification of the disease that is endorsed by the World Health Organization (WHO). Although the exact mechanisms of pulmonary vascular remodeling associated to PAH are still unclear, many contributing factors have been identified, including pulmonary endothelial dysfunction and excessive proliferation of pulmonary vascular cells. Indeed, pulmonary endothelial cells (EC) are recognized as major regulators of vascular function through their production of vasoconstrictors (e.g. ET-1, serotonin, angiotensin II) and vasodilators (nitric oxide and prostacyclin), of activators and inhibitors of smooth muscle cell (SMC) growth and migration, of prothrombotic and antithrombotic mediators, as well as of proinflammatory signals ${ }^{2}$. In healthy individuals a balance between these molecules is thought to mediate the low basal pulmonary vascular tone and homeostasis ${ }^{3}$. However, the dysfunctional endothelium displays to varying degrees an imbalanced production of several mediators leading towards an excess of vasoconstriction, smooth muscle hyperplasia and pulmonary vascular remodeling ${ }^{4-7}$. Furthermore, our group ${ }^{8}$ and other ${ }^{9}$ have clearly showed that both proliferation and survival of pulmonary EC in PAH are enhanced not only in situ, but also in vitro, when removed from their in vivo environment. An autocrine fibroblast growth factor (FGF)-2 activation loop is among the mechanisms that partly drive this abnormal hyperproliferative and apoptosis-resistant endothelial phenotype ${ }^{8}$. In addition, we obtained evidences that pulmonary EC from patients with idiopathic PAH release excessive amounts of soluble growth factors and cytokines able to act on different types of pulmonary vascular cells in the vascular wall (i.e. SMC, myofibroblasts, pericytes). In this altered EC-mural cell communication, many different endothelial factors have been found to be critical: paracrine overproduction of endothelin-1 (ET-1), FGF- ${ }^{8}$, serotonin (5-HT) ${ }^{10}$, angiotensin II (AngII) ${ }^{11,12}$ and leptin ${ }^{13}$. Furthermore, recent evidences also suggest that pulmonary vascular cells including EC exhibit a chronic shift in energy production from mitochondrial oxidative phosphorylation to glycolysis, a phenomenon that may participate to the pathogenesis ${ }^{7,14}$. The initial trigger for endothelial injury is not known, although hemodynamic forces (as shear stress), reactive oxygen species, toxins, inflammatory mediators and/or genetic predisposition are recognized as important modulators of endothelial dysfunction.

\section{The endothelin (ET)-1 signaling pathway in PAH}

The endothelins (ET-1, 2 and 3) constitute a family of 21 amino acid peptides that are encoded by a 38-amino-acid precursor known as big-endothelin. Endothelins are expressed in many tissues, 
including lung, brain, kidney, pituitary gland and placenta. ET-1 is one of the most potent vasoconstrictor protein produced by vascular EC. ET-1 is a small peptide ( 21 amino acid with two disulfide bridge) with the free carboxy terminal function involved in the activity of the peptide ${ }^{15}$. It results from the secretion of the inactive pre-pro-endothelin transformed in big-endothelin through endopeptidase action and finally to ET-1 via action of ET-1 converting enzyme (ECE). The ET-1 biosynthesis is stimulated by different stimuli, including hypoxia, growth factors, cytokines, shear stress, thrombin and angiotensin II (Figure 1). Among endogen vasoconstrictors, ET-1 is one of the stronger constrictors associated with the longer pharmacological effect ${ }^{16,17}$. In addition to vasoconstriction, ET-1 induces cellular proliferation, collagen deposition and inflammation. Although EC mainly produce ET-1, pulmonary arterial SMC and lung fibroblasts ${ }^{18}$ have been found to be a potential source of ET-1 ${ }^{19}$. ET-1 acts through two receptors, ETA and ETB. Both of these receptors are coupled to a Gq-protein and the formation of inositol triphosphate (IP3). Increased IP3 causes calcium release by the sarcoplasmic reticulum, which causes SMC contraction. Binding of ET-1 to ETA and ETB receptors on pulmonary arterial SMC promotes vasoconstriction, whereas activation of ETB receptors on EC causes vasodilation through increased $\mathrm{PGI}_{2}$ and $\mathrm{NO}$ levels ${ }^{20,}{ }^{21}$ associated with clearance elevation of circulating ET-1 22 (Table 1). In physiological conditions, ETB receptors have a vasodilator predominant effect; while in PAH, ETB receptors are up-regulated in pulmonary arterial SMC leading to vasoconstriction and proliferation ${ }^{16,23}$. ET-1 affinity for ETA receptors is 100 times higher than ET-3 whereas all the three isoforms have the same affinity for ETB receptors.

The pathogenic role of ET-1 for PAH pathophysiology has its roots on several crucial observations, among them: PAH patients have been reported to have higher plasma and lung ET-1 levels when compared with control subjects. A phenomenon that could be due to either increase ET-1 production by the pulmonary vasculature, reduced lung clearance, or a combination of these two processes ${ }^{24-26}$. Importantly, these ET-1 levels are correlated with the prognostic of the disease ${ }^{27-29}$. In addition, ET-1, ETA, and ETB expressions have been shown to be increased in experimental pulmonary hypertension ${ }^{30-32}$. All these observations have led to the development of effective oral treatments that are able to modulate the activity of ET-1 and that are currently used in the management of PAH.

\section{Endothelin receptor antagonists (ERAs)}

Prospective clinical randomized controlled trials (RCTs) have demonstrated efficacy and safety of three active ERA drugs (bosentan, ambrisentan, and macitentan) leading to their approval in the treatment of PAH. Chemical structures of these ERAs are shown in Figure 2. 


\subsection{Structure and specificity}

\section{Bosentan}

The discovery of ET-1 in 1988 led to the development of ERA based on pyrimidic sulfamide class of whom the Ro 46-2005 molecule, a dual antagonist ETA and ETB receptors has been selected ${ }^{33}$. In order to improve pharmacokinetic/pharmacodynamic properties, structural optimization was performed leading to the development of a new molecule: Ro 47-0203 (bosentan) in $1991^{16}$.

Bosentan is a non-peptide pyrimidine derivative that competitively antagonizes the binding of ET-1 to both ETA and ETB receptor subtypes, and irreversibly blocks their activities ${ }^{16}$. Bosentan has a specific inhibition on ET-1 receptors with non-binding to other receptors and was the first ERA studied in PAH and approved in PAH.

\section{Ambrisentan}

Selective ETA receptor inhibition has theoretical benefits by preserving vasodilator and clearance functions specific to ETB receptors, while preventing vasoconstriction and cellular proliferation mediated by ETA receptors ${ }^{34}$.

Based on this findings, ambrisentan, a highly selective ETA receptor antagonist has been developed ${ }^{35}$. Approved for sale by the U.S. Food and Drug Administration (FDA) in 2007 and in 2008 by the European Medicines Agency (EMA) ${ }^{36}$, it is the only selective ERA available in treatment of PAH. On the contrary to bosentan (sulfonamide ERA), ambrisentan belongs to the group of carboxylic ERA.

\section{Macitentan}

Macitentan is a new potent non-peptide non-selective ERA as bosentan (50-fold higher affinity for ETA than for ETB receptors). Development of macitentan leads to a high tissue-targeting and a sustained receptor binding compared to others ERA. The FDA and the EMA respectively approved Opsumit $^{\circledast}$ (macitentan) for the long-term treatment of PAH as monotherapy or in combination in adult patients of WHO Functional Class (FC) II to III, in October and december 2013. 


\subsection{Pharmacokinetics}

\section{Bosentan}

Bosentan as the other ERAs is an oral medication. The usual dosage is $125 \mathrm{mg}$ twice a day after a titration period of four weeks (62.5 mg twice a day). Bosentan is also approved for children with an available pediatric tablet formulation that has the same pharmacokinetic properties than the adult formulation $^{37}$. Pharmacokinetics of bosentan was mainly studied in healthy population. Data obtained from PAH patients indicates that exposition to bosentan is about two fold higher than in healthy population whereas pharmacokinetic of bosentan in pediatric $\mathrm{PAH}$ patients is comparable to that in healthy subjects.

The pharmacokinetic of bosentan is dose-dependent and proportional until $500 \mathrm{mg}$ per day. Higher dosages lead to a less proportional increase for Cmax and AUC. Following oral administration, bosentan reaches peak plasma concentrations in healthy subject after approximately 3 hours. The absolute bioavailability is about $50 \%$ which is not significantly modified with food at the recommended dose of $125 \mathrm{mg}$. Bosentan is highly bound to albumin (around 98\%), and does not enter in erythrocytes. No dosage adjustment in adults is required based on sex, age, ethnic origin and bodyweight. Steady-state concentrations are achieved within 3-5 days after multiple-dose administration with a volume of distribution of $30 \mathrm{~L}$ and a clearance of $17 \mathrm{~L} / \mathrm{h}{ }^{17}$. At steady-state, concentrations of bosentan are around $50-60 \%$ of the observed concentrations after once administration, probably due to induction of its metabolizing enzymes leading to 2-fold increase in its clearance. The metabolism of bosentan is mainly hepatic and involves cytochrome P450 (CYP) 2C9 and 3A4 with three identified metabolites eliminated by biliary excretion. Among these metabolites, Ro $48-5033$ is pharmacologically active and contributes to around $20 \%$ to the total response following administration of bosentan. Less than $3 \%$ of the oral dose of bosentan is found in urine leading that severe renal impairment (creatinine clearance $15-30 \mathrm{~mL} / \mathrm{min}$ ) doesn't have a clinically relevant influence on the pharmacokinetics of bosentan. While no dose adjustment is required in mild hepatic impairment (Child-Pugh class A), moderate and severe hepatic impairment lead to a contra-indication for bosentan therapy.

\section{Ambrisentan}


After oral administration ( 5 or $10 \mathrm{mg}$ once a day), ambrisentan is rapidly absorbed into the systemic circulation with a bioavability of about $90 \%{ }^{38}$. Food doesn't have any impact on this bioavability. In a Phase II trial in PAH patients, plasma levels of ambrisentan reached $C_{\max }$ between 1.7 and $3.3 \mathrm{~h}$ after oral administration, and the mean elimination half-life at steady state ranged from 9 to $15 \mathrm{~h}$, allowing the once-daily dosing ${ }^{39,40}$. Ambrisentan is highly bound to albumin in the same range of bosentan and is sparsely distributed in erythrocytes. Steady-state is obtained after 4 days of treatment. The main metabolic pathways of Ambrisentan are glucuronoconjugaison (13\%), oxidation by CYP 3A4 and in a lesser extend CYP 3A5 and CYP 2C19 leading to 4-hydroxyméthyl ambrisentan (21\%). Affinity of this metabolite on ETA receptors is 65 lesser than ambrisentan and doesn't be a part of pharmacology activity of the drug. Due to metabolisation, treatment with Ambrisentan should be avoided in severe hepatic impairment. Both biliary (around $80 \%$ ) and urinary (around $20 \%$ ) routes are involved in Ambrisentan excretion.

\section{Macitentan}

Selection of macitentan was based on inhibitory potency on both ET receptors and optimization of physicochemical properties to achieve high affinity for lipophilic environment ${ }^{41}$. Pharmacokinetic of macitentan is dose-proportional and characterize by slow absorption, due to low aqueous solubility. At a dose of $300 \mathrm{mg}$, macitentan has a median $t_{\max }$ of about $8 \mathrm{~h}$ and half-life of $17.5 \mathrm{~h}$ compatible with a once-day dosing regimen ${ }^{42,43}$. In vivo, macitentan is metabolized into a major and pharmacologically active metabolite, ACT-132577, which is formed by oxidative depropylation through the CYP 3A4. While ACT-132577 is 5-fold less potent than macitentan, its long half-life (about $48 \mathrm{~h}$ ) prones to accumulate upon repeated dosing and therefore significantly contributes to the overall effect. The urinary excretion is the most important route of elimination of drug-related material than faeces in humans. In urine, four entities were identified, with the hydrolysis product of ACT-373898 as the most abundant one. In faeces, five entities were identified, with the hydrolysis product of macitentan and ACT-132577 as the most abundant one ${ }^{44}$. Based on two prospective, single-center, open-label studies evaluated the pharmacokinetics of macitentan and its metabolites in healthy subjects and in subjects with mild, moderate, and severe hepatic impairment or severe renal function impairment, Sidharta et al., reported no clinically relevance and no dose adjustment in these populations treated with macitentan ${ }^{45}$. 


\subsection{Drug interactions}

\section{Bosentan}

Generally, multiple drug interactions with bosentan are reported due to its property of enzymatic induction of CYP 2C9, CYP 3A4 and probably also CYP 2C19 P-glycoprotein: Bosentan decreases exposure to ciclosporin, glibenclamide, simvastatin and warfarin by up to $50 \%$ because of induction of CYP $3 \mathrm{~A} 4$ and/or CYP 2C9. Regarding warfarin, which is often prescribed in PAH patients, no significant index normal ratio (INR) modifications were reported leading to no systematic doseadjustment required. However, an attentive monitoring of INR is recommended. Pharmacokinetic induction leads women taking bosentan not use hormone-based contraception alone due to a risk of pregnancy. Prgnancy is a contra-indication for women suffering from PAH because of a high risk of maternal mortality if the child is brought to term. Furthermore, bosentan is considered a teratogen, capable of causing fetal defects early in development. On the other hand, metabolization of bosentan through CYP 2 C9 and CYP $3 \mathrm{~A} 4$ leads to other drug interactions: Ketoconazole approximately doubles the exposure to bosentan because of inhibition of CYP 3A4. Co-administration of ciclosporin and bosentan markedly increases initial bosentan trough concentrations probably due to inhibition of bosentan transport protein in hepatocytes. Concomitant treatment with glibenclamide and bosentan leads to an increase in the incidence of aminotransferase elevations. Therefore, combined use with ciclosporin and glibenclamide is contraindicated and not recommended, respectively. Bosentan does not affect lopinavir and ritonavir exposure to a clinically relevant extent, but tolerability of bosentan should be monitored in human immunodeficiency virus patients under antiretroviral therapy with lopinavir/ritonavir. It is anticipated that all ritonavirboosted protease inhibitors will have a similar effect on bosentan pharmacokinetics ${ }^{46}$. Finally, in case of co-administration of bosentan and sildenafil in PAH, decrease of sildenafil associated with an increase of bosentan was reported. However, a lot of PAH patient combined these therapies and no clinical relevance was observed ${ }^{47}$. Finally, rifampicin is a potent inducer of CYP3A4 and CYP2C9 but is also known to inhibit several members of the organic anion transport (OAT) protein family involves in elimination of bosentan. Chronic treatment of rifampicine led to a more than $50 \%$ decrease in bosentan exposure. However, probably due to OAT inhibition, acute exposure of rifampicine led to a high levels of bosentan plasma concentration which could induce clinical concern with a higher risk of abnormal liver function. Therefore, it is recommended that liver function be assessed weekly for the first 4 weeks of concomitant administration ${ }^{48}$. 


\section{Ambrisentan}

On the contrary to bosentan, ambrisentan has low potential for drug-drug interactions explained by little effect on hepatic CYP450 induction or inhibition ${ }^{49}$. It can be safely administered with warfarin or sildenafil without dose adjustment ${ }^{50}$. Significant interaction was only reported with cyclosporine $A$ with a two fold increase of Ambrisentan concentration leading to fixed dose-adjustment at $5 \mathrm{mg}$ per day $^{48}$.

\section{Macitentan}

Although macitentan metabolism is indeed affected by CYP 3 A4 inhibition, the changes are not considered to be clinically significant and macitentan can be administered concomitantly with CYP $3 \mathrm{~A} 4$ inhibitors without need for dose adjustment ${ }^{51}$. Macitentan has a similar or higher potency for induction and inhibition of drug metabolizing enzymes and transporters than bosentan and seems to have same interactions. However, its low plasma concentration and minimal accumulation in the liver suggest that it will be markedly less prone to drug-drug interactions than bosentan ${ }^{52}$. Concomitant treatment with cyclosporine $A$ did not have any clinically relevant effect on the exposure to macitentan or its metabolites, at steady-state. Concomitant treatment with rifampin (a strong inducer of CYP 3A4) reduced significantly the exposure to macitentan and its metabolite ACT373898 at steady-state but did not affect the exposure to the active metabolite ACT-132577 to a clinically relevant extent ${ }^{53}$.

\subsection{Pharmacodynamics}

Several studies in animal models document that both selective and non selective ERAs prevent or attenuate experimental pulmonary hypertension $(\mathrm{PH})$ by inducing pulmonary vasodilation and decrease in pulmonary vascular remodeling and right ventricular (RV) hypertrophy.

\section{Bosentan}

In PH models induced by chronic hypoxia or monocrotaline (MCT), bosentan attenuates the increase in pulmonary artery pressures, prevents pulmonary vascular remodeling and decreases RV hypertrophy ${ }^{54-57}$. Regarding cardiac tissue, bosentan inhibits RV collagen expression in rats exposed to chronic hypoxia ${ }^{56}$. In addition to these effects, bosentan has been reported to inhibit pulmonary 
arterial SMC proliferation of and inflammatory response in pulmonary tissue to injection of ET-1 in guinea pig and mouse lung ${ }^{58-60}$. Moreover, in PAH patients, a treatment with bosentan led to a reduction of ICAM-1 and plasmatic IL- 6 levels that correlated with hemodynamic improvement ${ }^{61}$.

\section{Ambrisentan}

On the contrary with others ERAs, there are no experimental data on the effects of ambrisentan in $\mathrm{PH}$. Regarding inflammation, a treatment with ambrisentan decreases pro-inflammatory genes expression in ischemia/reperfusion models, leading to a cytoprotective effect on vascular microcirculation ${ }^{62}$.

\section{Macitentan}

Macitentan is a competitive ERA with significantly slower receptor dissociation kinetics than the currently approved ERAs. Slow dissociation caused insurmountable antagonism in functional pulmonary arterial SMC-based assays and this could contribute to an enhanced pharmacological activity of macitentan in PAH ${ }^{63}$. In functional assays, macitentan and ACT-132577 inhibited ET-1induced contractions in isolated endothelium-denuded rat aorta (ETA receptors) and sarafotoxin S6cinduced contractions in isolated rat trachea (ETB receptors). Macitentan increased binding to receptors as compared to existing ERAs indicating a more potent pharmacological activity in vivo ${ }^{41}$ ${ }^{64}$. In PH rats, macitentan prevented both the increase in pulmonary pressures and RV hypertrophy, and it improved survival, without effect on systemic arterial blood pressure ${ }^{41}$.

\subsection{Efficacy of ERAs in PAH}

The use of ERA in PAH management is relatively new. Bosentan $\left(\operatorname{Tracleer}^{\circledR}\right)$, Ambrisentan (Volibris ${ }^{\circledR}$ ) and recently macitentan (Opsumit ${ }^{\circledR}$ ) have been approved in the last twelve years.

\section{Bosentan}


Bosentan is the first ERA and the first oral medication approved in PAH. Its availability represents a major progress in the management of the disease by improving clinical status, exercise capacity and hemodynamic parameters, and delaying clinical worsening in PAH ${ }^{24,65,66}$. Moreover, Bosentan significantly improves quality of life in patients with idiopathic PAH or PAH associated with connective tissue diseases ${ }^{67}$. Three pivotal studies led to bosentan approval for idiopathic and heritable PAH as well as PAH associated with connective tissue disease ${ }^{65,66,68}$. More recently, it was also approved for PAH associated with congenital heart disease ${ }^{69}$. Table 2 summarized RCTs performed with bosentan and other ERA.

In the first pilot study, performed in 32 patients with idiopathic PAH and PAH associated with connective tissue diseases, a 12-week treatment with bosentan was shown to improve exercise capacity (6-min walk distance) and pulmonary haemodynamics ${ }^{65}$. The pivotal study BREATHE-1, confirmed these previous findings with bosentan leading to a significant improvement in exercise capacity, as well as delaying time to clinical worsening in patients with functional class III-IV PAH ${ }^{66}$. In patients with mildly symptomatic PAH (i.e. functional class II), the EARLY study showed that bosentan prevented clinical deterioration (delayed time to clinical worsening) without significant improvement in exercise capacity ${ }^{68}$.

In the RCT BREATHE-5, bosentan was shown to improve 6-min walk distance without deterioration in oxygen saturation in patients with $\mathrm{PAH}$ associated with non-repaired congenital pulmonary-tosystemic shunt (Eisenmenger's syndrome) ${ }^{69}$.

Bosentan was also shown to be notably effective in other forms of PAH in open-label trials. In the BREATHE-4 study performed in 16 patients with PAH associated with HIV infection, a 16-week treatment with bosentan led to a major improvement in haemodynamics and exercise capacity without any change in the control of HIV infection ${ }^{70}$, portopulmonary hypertension (PoPH) were usually excluded from RCT with ERAs and there is no approval for bosentan in this indication. However, several non-controlled studies have shown that PoPH patients with mild to moderate cirrhosis (i.e. Child-Pugh score A or B) or extra-hepatic portal hypertension (e.g. portal thrombosis) may benefit from bosentan with an acceptable safety profile ${ }^{71}$.

In long-term retrospective observational studies of bosentan in children with idiopathic PAH or PAH associated with congenital heart diseases or connective tissue diseases, bosentan was reported to be safe and effective in slowing disease progression ${ }^{72,73}$.

\section{Ambrisentan}


Ambrisentan was studied in two phase III placebo-controlled trials, ARIES-1 ( $n=202$, doses of 5 or 10 mg qd for 12 weeks) and ARIES-2 ( $n=192$, doses of 2.5 and $5 \mathrm{mg}$ qd for 12 weeks), in patients with idiopathic or heritablePAH, PAH associated with connective tissue disease, anorexigen use or HIV infection ${ }^{36}$. The primary endpoint was change from baseline in 6-min walk distance (6MWD) at week 12. The 6MWD increased in all ambrisentan groups with mean placebo-corrected treatment effects of $31 \mathrm{~m}$ to $59 \mathrm{~m}$. Improvements in time to clinical worsening, functional class, quality of life (SF-36 score), Borg dyspnea score, and B-type natriuretic peptide were also observed. No patient treated with ambrisentan developed aminotransferase concentrations $>3$ times the upper limit of normal. In the extension phase of these studies (ARIES-E) ${ }^{74}$, a 2 -year treatment with ambrisentan was associated with sustained improvements in exercise capacity and a low risk of clinical worsening and death. Ambrisentan was generally well tolerated and had a low risk of aminotransferase serum level elevation over the study period. Another long term study of ambrisentan in PAH reported similar sustained benefit in exercise capacity and pulmonary hemodynamics ${ }^{75}$.

\section{Macitentan}

Macitentan was studied in amulticenter, double-blind, placebo-controlled, long-term, event-driven randomized study (SERAPHIN, Study with an Endothelin Receptor Antagonist in Pulmonary arterial Hypertension to Improve cliNical outcome) ${ }^{76}$. This study, the first using a morbidity-mortality composite endpoint, was designed to evaluate the efficacy and safety of macitentan through the primary endpoint of time to first morbidity and all-cause mortality event in 742 patients with symptomatic PAH and treated for up to three and a half years. Macitentan, at both the doses of $3 \mathrm{mg}$ qd and $10 \mathrm{mg}$ qd, has met the primary endpoint, decreasing the risk of a morbidity/mortality event over the treatment period versus placebo. This risk was reduced by 45 percent in the $10 \mathrm{mg}$ dose group $(P<0.0001)$. At $3 \mathrm{mg}$, the observed risk reduction was 30 percent $(P=0.0108)$. Worsening of PAH was the main event contributing to primary endpoint. Interestingly, macitentan $10 \mathrm{mg}$ significantly reduced the risk of primary endpoint event vs placebo in both treatment-naïve patients and patients on background therapy at study entry (sildenafil in the vast majority of cases). Macitentan also significantly improved clinically important secondary endpoints including 6MWD, NYHA FC and PAH-related death or hospitalization. Treatment with macitentan in the SERAPHIN study was well tolerated and the more frequently reported adverse events were headache, nasopharyngitis and anemia. Elevations of liver aminotransferases greater than 3 times the upper limit of normal were observed in 4.5 percent of patients receiving placebo, in 3.6 percent of patients on $3 \mathrm{mg}$ of macitentan and in 3.4 percent of patients on $10 \mathrm{mg}$ of macitentan. In addition, no 
difference was observed between macitentan and placebo on occurrence of peripheral edema. A decrease in hemoglobin - reported as an adverse event - was observed more frequently on macitentan than placebo, with no difference in treatment discontinuation between groups ${ }^{76}$. Macitentan $10 \mathrm{mg}$ has been recently approved by the FDA and the EMA in the specialty name of Opsumit ${ }^{\circledR}$ based on the results of SERAPHIN study.

\subsection{Tolerability}

\subsubsection{General side effects}

General side effects of ERAs are related to vasodilator properties as headache, peripheral edema, nasal congestion, flushing or nausea and are dose-dependent. Hypotension and palpitations could also be reported in a treatment with ERA. Among ERAs available in PAH, macitentan seems to be the most tolerated regarding vasodilation ${ }^{42}$. However, this observation could be explained by the limited use of macitentan which has just obtained its approval in the United States and in the European Union.

\subsubsection{Elevation in hepatic aminotransferases}

This is the main side effect observed with ERAs. A true hepatotoxicity was observed with sitaxsentan, another selective ETA receptor antagonist previously available in Europe, Australia and Canada ${ }^{77}$, leading to its withdrawal from the market after cases of fatal liver toxicity ${ }^{78-81}$.

Bosentan is known to be associated with reversible, dose-dependent and in most cases asymptomatic elevation of aminotransferases ${ }^{82}$. This increase in liver enzymes usually appears during the first six months of treatment with bosentan but could also occur later. In order to prevent this adverse event, a gradual dosage increase is recommended (62.mg twice a day the first month, and $125 \mathrm{mg}$ twice a day thereafter). In the same way, aminotransferase elevation could normalize after decrease of bosentan dosage. Mechanism of this toxicity is actually not fully understood. It has been hypothesized that it could be a consequence of the cellular accumulation of bile salts due to impaired canalicular excretion from bile salt export pump (BSEP) inhibition ${ }^{83}$. Another hypothesis resides in the demonstration that bosentan, but not ambrisentan, inhibits four human hepatic transporters, providing a potential mechanism for the increased hepatotoxicity observed with bosentan ${ }^{84}$. Genetic variability of enzymes involved in drug metabolism is a preponderant susceptibility factor for druginduced liver injury and was hypothesis in bosentan liver toxicity: It can influence the metabolism of bosentan in a variety of ways. Recently, Markova et al. identified CYP2C9*2 as a potential genetic 
marker for bosentan-induced liver injury, despite a modest effect on bosentan metabolism ${ }^{85}$. However, results of this study were not marked and additional studies are needed to validate this hypothesis. Another study published in June 2014 does not support CYP2C9*2 as a genetic marker of bosentan-induced liver injury. Moreover, functional polymorphisms of genes involved in bosentan pharmacokinetics (SLCO1B1, SLCO1B3, and CYP2C9*3) or in hepato- biliary transporters affected by bosentan ( $A B C B 11$ ) were not found to be associated with bosentan-induced hepatotoxicity ${ }^{86}$. Other mechanisms could be also involved in this toxicity as accumulation of bosentan in hepatocytes leading to cytolysis or an immune-allergic pathway.

In order to obtain further safety data of bosentan, European authorities required the introduction of a post-marketing surveillance system. Within 30 months, this system has assembled data from 4,994 patients, representing $79 \%$ of those exposed to bosentan in Europe during that time period ${ }^{87}$. The reported annual rate of aminotransferase level elevation was $10.1 \%$, and $3.2 \%$ of patients had to discontinue the drug for this reason. Aminotransferase level elevation was reversible in all cases, and there was no permanent liver injury. In order to afford the best efficacy/safety balance for PAH patients, a monthly monitoring of hepatic aminotransferase is mandatory in patients treated with bosentan. In the same way, in the case of dosage modification and/or potentially drug-drug interaction, a monitoring has to be performed (after 2 weeks).

Ambrisentan has not been shown to increase the risk of liver enzyme elevation over placebo ${ }^{88}$. Based on the data obtained from the risk minimization action plan, the FDA removed in March 2011 the requirement of mandatory monthly monitoring of liver function tests with ambrisentan therapy ${ }^{89}$. However, monitoring is still required by the EMA. Ambrisentan belongs to the group of carboxylic ERAs which, unlike sulfonamide ERAs, are devoid of hepatotoxicity. Ambrisentan is a safe alternative when bosentan has to be discontinued because of increased liver aminotransferase levels ${ }^{88}$. Among 31 patients who discontinued bosentan, none of them had a recurrence of liver enzyme elevation necessitating ambrisentan discontinuation and only one patient presented transient elevated aminotransferases resulting in a dose reduction with no further elevations. However, as elevations in liver aminotransferases induced by ERAs are typically seen after repeated dosing and sometimes only after months of treatment ${ }^{87}$. The results of the ARIES-E study, the long-term open-label extension of both ARIES-1 and ARIES-2 studies with ambrisentan, showed that the annual incidence rate of elevation of AST/ALT level of more than 3 times the upper limit of normal was about $2 \%{ }^{74}$.

Macitentan does not inhibit canalicular bile acid transport in rats, which could lead to better liver safety profile than bosentan ${ }^{90}$. In the SERAPHIN study, the incidence of aminotransferase levels 
more than 3 times the upper limit of normal were similar to the placebo group ${ }^{76}$. However, due to the limited use of macitentan, these safety results need to be confirmed in the next years.

\subsubsection{Edema}

Peripheral edema is another side effects observed with ERAs use. One recent explanation is the upregulation of myocardial ET axis in right heart failure during $\mathrm{PH}$ which could be a compensatory mechanism to preserve RV contractility, as the afterload increases. ERAs use might therefore potentially worsen RV function explaining some of the peripheral edema noted clinically with these agents ${ }^{91}$. Moreover, there is a higher incidence of peripheral edema observed in PAH patients treated with ambrisentan, compared with dual ERAs ${ }^{92}$. In studies comparing bosentan or macitentan with placebo, the occurrence of peripheral edema was similar in active-treatment and placebo groups ${ }^{66,76}$. One possible explanation for different rates of edema with selective versus dual ERAs may reflect differences in affinities to the ETA receptor ${ }^{92}$. Another potential explanation may involve the renin/angiotensin system (RAS): Selective ETA receptor blockade during early congestive heart failure caused sustained sodium retention by activating the RAS, resulting in edema ${ }^{93}$. Finally, a study in rats comparing bosentan vs sitaxsentan suggested that ERA-induced fluid retention was occurring by activation of the vasopressin system via secondary stimulation by ET of the uninhibited ETB receptors ${ }^{94}$. Recently, Maron et al., analyzed the association of spironolactone and ET-A receptor antagonism in order to avoid edema side effect ${ }^{95}$. This study reported that use of spironolactone may be clinically beneficial in PAH despite prospective clinical trials are required to further characterize these findings ${ }^{95}$.

\subsubsection{Anemia}

Decreased hemoglobin levels and anemia are other biologic side effects that could appear during ERA treatment. However, this adverse event is rare and usually manageable. The mechanism of the decrease in hemoglobin level is not fully understood. This decrease could be related to the hemodilution induced by vasodilation and intravascular fluid retention. A direct effect of ERAs on hematopoiesis has never been demonstrated. In clinical placebo-controlled studies, decrease of hemoglobin levels induced by bosentan have been stabilized after 4 to 12 weeks of treatment. A monitoring of hemoglobin is therefore recommended before initiation of the treatment, monthly the first 4 months and then quarterly. A monitoring is also recommended with ambrisentan therapy the first and the third month after its introduction and thereafter periodically depending on clinical practice (ref RCP ambrisentan). In the SERAPHIN study, macitentan was shown to induce hemoglobin 
concentration in a dose-dependent fashion without any evidence of fluid retention and hemodilution 96.

\subsubsection{Teratogenicity}

Due to teratogenic effects reported in animals treated with bosentan, pregnancy is a formally contraindicated ${ }^{97}$. In childbearing women, bosentan and ambrisentan could be prescribed if contraception is proved associated with a negative pregnancy test performed before initiation of the treatment and, thereafter, monthly. Type of contraception is particularly essential, notably with bosentan: estroprogestative contraception, whatever its administration route, is not reliable due to powerful enzymatic induction on CYP 2C9 and CYAP 3A4. Consequently, a double contraception is required. Similar to other members of its drug class, macitentan carries a boxed warning alerting patients and healthcare professionals that the drug should not be used in pregnant women, because it can harm the developing fetus. In addition to teratogenic properties of ERAs, pregnancy is a formal contra-indication in $\mathrm{PAH}$ as it could be an aggravating factor in the prognosis of the disease.

\section{Place of ERAs in the treatment algorithm for PAH}

In the past fifteen years, the number of available specific therapies for PAH management has markedly increased. Today 9 drugs are approved for the treatment of patient with PAH including prostacyclin analogues (epoprostenol, treprostinil, iloprost), ERAs (bosentan, ambrisentan, macitentan) and drugs targeting the NO/cGMP pathway (two PDE5 inhibitors sildenafil and tadalafil, and the guanylate cyclase activator riociguat).

ERAs have proven their efficacy with a relative few side effects leading to be an attractive option, either in monotherapy or in combination therapy with drugs targeting the other pathways. The three ERAs are currently recommended as first line therapy in functional class II and III PAH patients. The advantage of ambrisentan and macitentan over bosentan is the once daily oral dose leading to improve the quality of life and adherence of PAH patients. Moreover, the reduction of hepatic adverse events compared with bosentan seems to be a clinical argument for the choice of therapy. However, more data are needed in the long term to confirm this observation, especially with macitentan. Regarding the general safety profile, macitentan appears to be more safe and has a low propensity for drug-drug interactions in addition with no dose adjustments required in patients with renal or hepatic impairment 


\section{Conclusions and Future Directions}

ERAs were the first oral therapy for PAH and remain a critical component of the therapeutic algorithm in the management of the disease. ERAs demonstrated improvements in pulmonary hemodynamics, exercise capacity, functional status and clinical outcome in several randomized placebo-controlled trials representing therefore a major therapy in PAH. Current clinical data suggest that both dual and specific ERAs have a similar efficacy in improving clinical outcome in PAH patients with differences in safety profile. Data on the long term with macitentan will be needed to confirm its place in PAH treatment. 


\section{Figures}

Figure 1: The endothelin (ET-1) signaling system

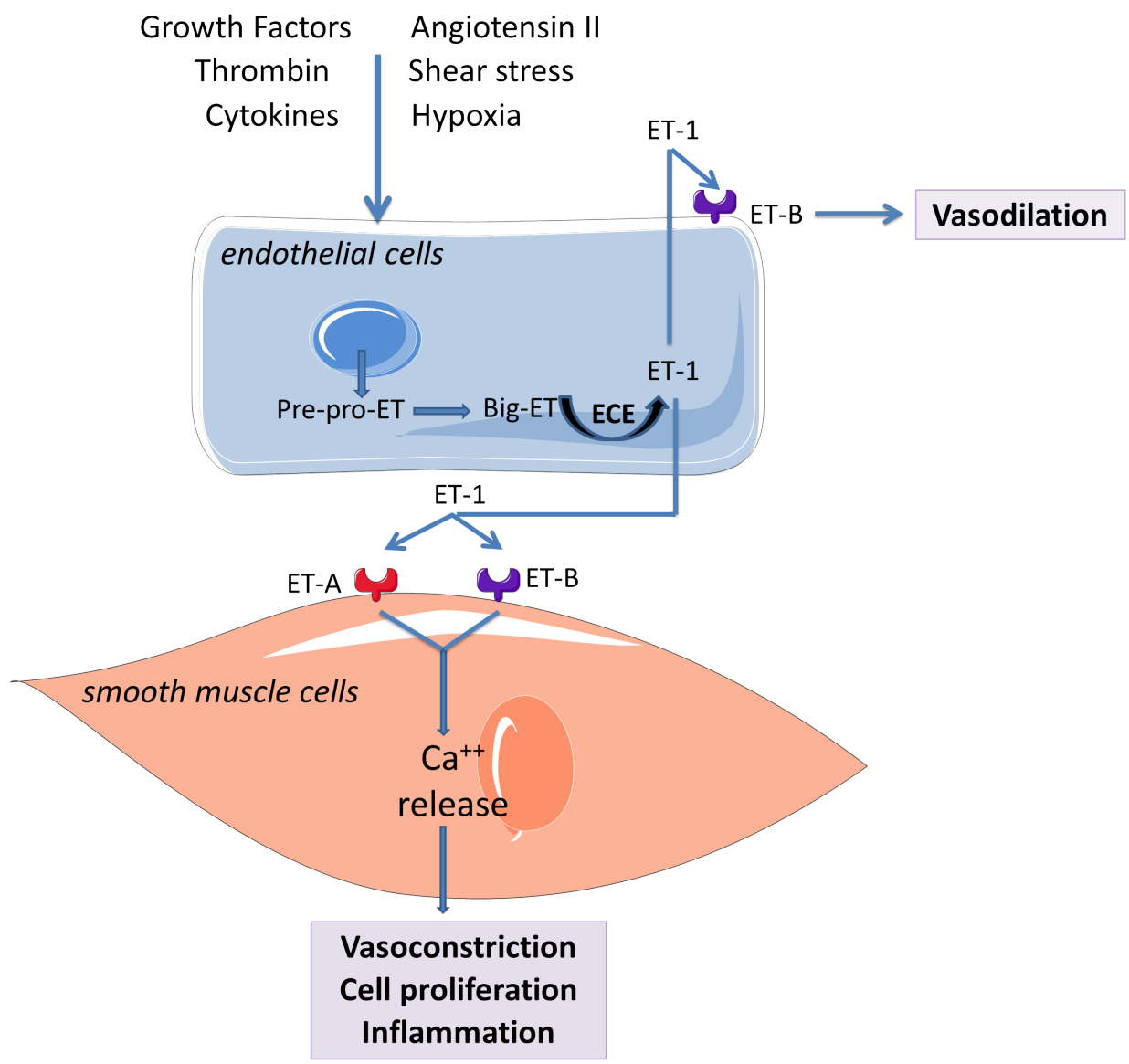

Figure 2: Chemical structures of the three available endothelin receptor antagonists (ERAs)

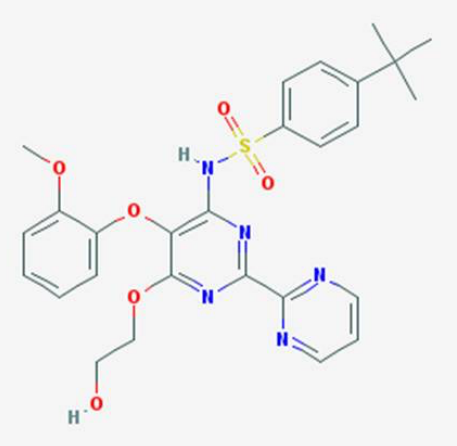

Bosentan

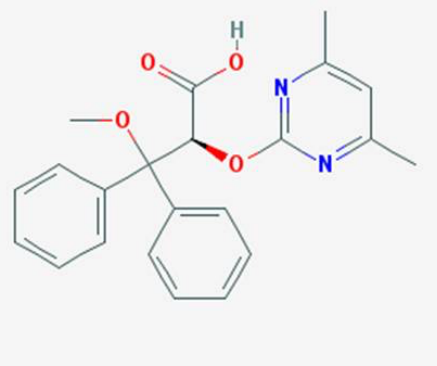

Ambrisentan

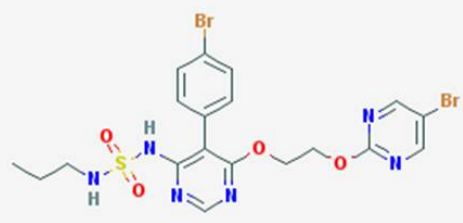

Macitentan 
Table 1: Localization of $E T_{A}$ and $E T_{B}$ receptors and biological effects after binding with $E T-1$

\begin{tabular}{|c|c|c|}
\hline \multirow[t]{2}{*}{$\mathrm{ET}_{\mathrm{A}}$} & Localization & $\begin{array}{l}\text { Smooth muscle cells } \\
\text { Heart (cardiomyocytes) }\end{array}$ \\
\hline & Biological effects & $\begin{array}{l}\text { Vasoconstriction } \\
\text { Cellular proliferation } \\
\text { Tissue hypertrophy } \\
\text { Fibrosis }\end{array}$ \\
\hline \multirow[t]{2}{*}{$\mathrm{ET}_{\mathrm{B}}$} & Localization & $\begin{array}{l}\text { Smooth muscle cells Endothelium } \\
\text { Heart (fibroblasts) } \\
\text { Adrenal gland }\end{array}$ \\
\hline & Biological effects & $\begin{array}{l}\text { Vasoconstriction } \\
\text { Vasodilatation } \\
\text { Hypertrophy, fibrosis, apoptosis } \\
\text { Aldosterone production }\end{array}$ \\
\hline
\end{tabular}


Table 2: Pivotal randomized clinical trials with endothelin receptor antagonists

\begin{tabular}{|c|c|c|c|c|c|c|c|}
\hline Drug & $\begin{array}{c}\text { Study } \\
\text { acronym }\end{array}$ & PAH etiologies & $\begin{array}{l}\text { Number of } \\
\text { patients }\end{array}$ & $\begin{array}{l}\text { NYHA FC at } \\
\text { inclusion }\end{array}$ & $\begin{array}{l}\text { Study duration } \\
\text { (weeks) }\end{array}$ & $\begin{array}{l}\text { Primary } \\
\text { endpoint }\end{array}$ & Reference \\
\hline \multirow[t]{4}{*}{ Bosentan } & Study 351 & iPAH, hPAH, PAH-CTD & 32 & III-IV & 12 & 6-MWD & 65 \\
\hline & BREATHE-1 & iPAH, hPAH, PAH-CTD & 213 & III-IV & 16 & 6-MWD & 66 \\
\hline & BREATHE-5 & PAH-CHD (Eisenmenger's) & 54 & III & 18 & $\mathrm{SpO}_{2}$ and $\mathrm{PVR}$ & 68 \\
\hline & EARLY & $\begin{array}{c}\text { iPAH, hPAH, PAH-CTD, } \\
\text { PAH-HIV, PAH-CHD (repaired) }\end{array}$ & 185 & II & 24 & 6-MWD and PVR & 69 \\
\hline Ambrisentan & ARIES-1 \& 2 & $\begin{array}{c}\text { iPAH, hPAH, PAH-anorexigens, PAH- } \\
\text { CTD, PAH-HIV }\end{array}$ & $\begin{array}{c}394 \\
(202 \& 192)\end{array}$ & I-IV & 12 & 6-MWD & 36 \\
\hline Macitentan & SERAPHIN & $\begin{array}{c}\text { iPAH, hPAH, PAH-drugs and toxins; } \\
\text { PAH-CHD (repaired) }\end{array}$ & 742 & II-IV & $\begin{array}{l}\text { Event-driven : } \\
85 \text { (placebo) to } \\
104(10 \mathrm{mg})\end{array}$ & Morbi-mortality* & 76 \\
\hline
\end{tabular}

List of abbreviations: PAH: pulmonary arterial hypertension; iPAH: idiopathic PAH; hPAH: heritable PAH; PAH-CTD: PAH associated with connective tissue diseases; PAH-CHD: PAH associated with congenital heart diseases; PAH-HIV: PAH associated with the human immunodeficiency virus infection; 6-MWD: 6minute walk distance; PVR: pulmonary vascular resistance; $\mathrm{SpO}_{2}$ : systemic pulse oximetry.

* In the SERAPHIN study, the primary end point was the time from the initiation of treatment to the first occurrence of a composite end point of death, atrial septostomy, lung transplantation, initiation of treatment with intravenous or subcutaneous prostanoids, or worsening of PAH. 


\section{References}

1. O'Callaghan DS, Savale L, Montani D, Jais X, Sitbon O, Simonneau G, Humbert M. Treatment of pulmonary arterial hypertension with targeted therapies. Nat Rev Cardiol.8:526-538

2. Stevens T. Functional and molecular heterogeneity of pulmonary endothelial cells. Proceedings of the American Thoracic Society. 2011;8:453-457

3. Dinh-Xuan AT. Endothelial modulation of pulmonary vascular tone. Eur Respir J. 1992;5:757762

4. Humbert M, Morrell NW, Archer SL, Stenmark KR, MacLean MR, Lang IM, Christman BW, Weir EK, Eickelberg O, Voelkel NF, Rabinovitch M. Cellular and molecular pathobiology of pulmonary arterial hypertension. Journal of the American College of Cardiology. 2004;43:13S$24 \mathrm{~S}$

5. Hansmann G, de Jesus Perez VA, Alastalo TP, Alvira CM, Guignabert C, Bekker JM, Schellong $\mathrm{S}$, Urashima T, Wang L, Morrell NW, Rabinovitch M. An antiproliferative bmp2/ppargamma/apoe axis in human and murine smcs and its role in pulmonary hypertension. The Journal of clinical investigation. 2008;118:1846-1857

6. Morrell NW, Adnot S, Archer SL, Dupuis J, Jones PL, MacLean MR, McMurtry IF, Stenmark KR, Thistlethwaite PA, Weissmann N, Yuan JX, Weir EK. Cellular and molecular basis of pulmonary arterial hypertension. Journal of the American College of Cardiology. 2009;54:S2031

7. Guignabert C, Tu L, Le Hiress M, Ricard N, Sattler C, Seferian A, Huertas A, Humbert M, Montani D. Pathogenesis of pulmonary arterial hypertension: Lessons from cancer. European respiratory review : an official journal of the European Respiratory Society. 2013;22:543-551

8. Tu L, Dewachter L, Gore B, Fadel E, Dartevelle P, Simonneau G, Humbert M, Eddahibi S, Guignabert C. Autocrine fibroblast growth factor-2 signaling contributes to altered endothelial phenotype in pulmonary hypertension. American journal of respiratory cell and molecular biology. 2011;45:311-322

9. Masri FA, Xu W, Comhair SA, Asosingh K, Koo M, Vasanji A, Drazba J, Anand-Apte B, Erzurum SC. Hyperproliferative apoptosis-resistant endothelial cells in idiopathic pulmonary arterial hypertension. American journal of physiology. Lung cellular and molecular physiology. 2007;293:L548-554

10. Dewachter L, Adnot S, Fadel E, Humbert M, Maitre B, Barlier-Mur AM, Simonneau G, Hamon $M$, Naeije R, Eddahibi S. Angiopoietin/tie2 pathway influences smooth muscle hyperplasia in idiopathic pulmonary hypertension. Am J Respir Crit Care Med. 2006;174:1025-1033

11. de Man FS, Tu L, Handoko ML, Rain S, Ruiter G, Francois C, Schalij I, Dorfmuller P, Simonneau G, Fadel E, Perros F, Boonstra A, Postmus PE, van der Velden J, Vonk-Noordegraaf A, Humbert M, Eddahibi S, Guignabert C. Dysregulated renin-angiotensin-aldosterone system contributes to pulmonary arterial hypertension. Am J Respir Crit Care Med. 2012;186:780789

12. de Man FS, Handoko ML, Guignabert C, Bogaard HJ, Vonk-Noordegraaf A. Neurohormonal axis in patients with pulmonary arterial hypertension: Friend or foe? Am J Respir Crit Care Med. 2013;187:14-19

13. Huertas A, Tu L, Gambaryan N, Girerd B, Perros F, Montani D, Fabre D, Fadel E, Eddahibi S, Cohen-Kaminsky S, Guignabert C, Humbert M. Leptin and regulatory t-lymphocytes in idiopathic pulmonary arterial hypertension. Eur Respir J. 2012;40:895-904

14. Xu W, Koeck T, Lara AR, Neumann D, DiFilippo FP, Koo M, Janocha AJ, Masri FA, Arroliga AC, Jennings C, Dweik RA, Tuder RM, Stuehr DJ, Erzurum SC. Alterations of cellular bioenergetics in pulmonary artery endothelial cells. Proceedings of the National Academy of Sciences of the United States of America. 2007;104:1342-1347 
15. Inoue A, Yanagisawa M, Kimura S, Kasuya Y, Miyauchi T, Goto K, Masaki T. The human endothelin family: Three structurally and pharmacologically distinct isopeptides predicted by three separate genes. Proceedings of the National Academy of Sciences of the United States of America. 1989;86:2863-2867

16. Clozel M, Breu V, Gray GA, Kalina B, Loffler BM, Burri K, Cassal JM, Hirth G, Muller M, Neidhart W, et al. Pharmacological characterization of bosentan, a new potent orally active nonpeptide endothelin receptor antagonist. The Journal of pharmacology and experimental therapeutics. 1994;270:228-235

17. Dingemanse J, van Giersbergen PL. Clinical pharmacology of bosentan, a dual endothelin receptor antagonist. Clinical pharmacokinetics. 2004;43:1089-1115

18. Shi-Wen X, Chen Y, Denton CP, Eastwood M, Renzoni EA, Bou-Gharios G, Pearson JD, Dashwood M, du Bois RM, Black CM, Leask A, Abraham DJ. Endothelin-1 promotes myofibroblast induction through the eta receptor via a rac/phosphoinositide 3-kinase/aktdependent pathway and is essential for the enhanced contractile phenotype of fibrotic fibroblasts. Mol Biol Cell. 2004;15:2707-2719

19. Markewitz BA, Farrukh IS, Chen Y, Li Y, Michael JR. Regulation of endothelin-1 synthesis in human pulmonary arterial smooth muscle cells. Effects of transforming growth factor-beta and hypoxia. Cardiovasc Res. 2001;49:200-206

20. Eguchi S, Hirata Y, Imai T, Marumo F. Endothelin receptor subtypes are coupled to adenylate cyclase via different guanyl nucleotide-binding proteins in vasculature. Endocrinology. 1993;132:524-529

21. Seo B, Oemar BS, Siebenmann R, von Segesser L, Luscher TF. Both eta and etb receptors mediate contraction to endothelin-1 in human blood vessels. Circulation. 1994;89:1203-1208

22. Masaki T. Possible role of endothelin in endothelial regulation of vascular tone. Annual review of pharmacology and toxicology. 1995;35:235-255

23. Kim NH, Rubin L. Endothelin in health and disease: Endothelin receptor antagonists in the management of pulmonary artery hypertension. Journal of cardiovascular pharmacology and therapeutics. 2002;7:9-19

24. Giaid A, Yanagisawa M, Langleben D, Michel RP, Levy R, Shennib H, Kimura S, Masaki T, Duguid WP, Stewart DJ. Expression of endothelin-1 in the lungs of patients with pulmonary hypertension. The New England journal of medicine. 1993;328:1732-1739

25. Cacoub P, Dorent R, Nataf P, Carayon A, Riquet M, Noe E, Piette JC, Godeau P, Gandjbakhch I. Endothelin-1 in the lungs of patients with pulmonary hypertension. Cardiovasc Res. 1997;33:196-200

26. Dupuis J, Cernacek P, Tardif JC, Stewart DJ, Gosselin G, Dyrda I, Bonan R, Crepeau J. Reduced pulmonary clearance of endothelin-1 in pulmonary hypertension. American heart journal. 1998;135:614-620

27. Silva Marques J, Martins SR, Calisto C, Goncalves S, Almeida AG, de Sousa JC, Pinto FJ, Diogo AN. An exploratory panel of biomarkers for risk prediction in pulmonary hypertension: Emerging role of ct-proet-1. The Journal of heart and lung transplantation : the official publication of the International Society for Heart Transplantation. 2013;32:1214-1221

28. Montani D, Souza R, Binkert C, Fischli W, Simonneau G, Clozel M, Humbert M. Endothelin1/endothelin-3 ratio: A potential prognostic factor of pulmonary arterial hypertension. Chest. 2007;131:101-108

29. Rubens C, Ewert R, Halank M, Wensel R, Orzechowski HD, Schultheiss HP, Hoeffken G. Big endothelin-1 and endothelin-1 plasma levels are correlated with the severity of primary pulmonary hypertension. Chest. 2001;120:1562-1569

30. Frasch HF, Marshall C, Marshall BE. Endothelin-1 is elevated in monocrotaline pulmonary hypertension. The American journal of physiology. 1999;276:L304-310

31. Stelzner TJ, O'Brien RF, Yanagisawa M, Sakurai T, Sato K, Webb S, Zamora M, McMurtry IF, Fisher JH. Increased lung endothelin-1 production in rats with idiopathic pulmonary hypertension. The American journal of physiology. 1992;262:L614-620 
32. Miyauchi T, Yorikane R, Sakai S, Sakurai T, Okada M, Nishikibe M, Yano M, Yamaguchi I, Sugishita Y, Goto K. Contribution of endogenous endothelin-1 to the progression of cardiopulmonary alterations in rats with monocrotaline-induced pulmonary hypertension. Circulation research. 1993;73:887-897

33. Clozel M, Breu V, Burri K, Cassal JM, Fischli W, Gray GA, Hirth G, Loffler BM, Muller M, Neidhart $\mathrm{W}$, et al. Pathophysiological role of endothelin revealed by the first orally active endothelin receptor antagonist. Nature. 1993;365:759-761

34. Wilkins MR. Selective or nonselective endothelin receptor blockade in pulmonary arterial hypertension. Am J Respir Crit Care Med. 2004;169:433-434

35. Riechers $\mathrm{H}$, Albrecht HP, Amberg W, Baumann E, Bernard H, Bohm HJ, Klinge D, Kling A, Muller S, Raschack M, Unger L, Walker N, Wernet W. Discovery and optimization of a novel class of orally active nonpeptidic endothelin-a receptor antagonists. Journal of medicinal chemistry. 1996;39:2123-2128

36. Galie N, Olschewski H, Oudiz RJ, Torres F, Frost A, Ghofrani HA, Badesch DB, McGoon MD, McLaughlin VV, Roecker EB, Gerber MJ, Dufton C, Wiens BL, Rubin L. Ambrisentan for the treatment of pulmonary arterial hypertension: Results of the ambrisentan in pulmonary arterial hypertension, randomized, double-blind, placebo-controlled, multicenter, efficacy (aries) study 1 and 2. Circulation. 2008;117:3010-3019

37. Gutierrez MM, Nicolas LB, Donazzolo Y, Dingemanse J. Relative bioavailability of a newly developed pediatric formulation of bosentan vs. The adult formulation. International journal of clinical pharmacology and therapeutics. 2013;51:529-536

38. Casserly B, Klinger JR. Ambrisentan for the treatment of pulmonary arterial hypertension. Drug design, development and therapy. 2009;2:265-280

39. Galie N, Badesch D, Oudiz R, Simonneau G, McGoon MD, Keogh AM, Frost AE, Zwicke D, Naeije R, Shapiro S, Olschewski H, Rubin LJ. Ambrisentan therapy for pulmonary arterial hypertension. Journal of the American College of Cardiology. 2005;46:529-535

40. Vidal. Rcp volibris.

41. Iglarz M, Binkert C, Morrison K, Fischli W, Gatfield J, Treiber A, Weller T, Bolli MH, Boss C, Buchmann S, Capeleto B, Hess P, Qiu C, Clozel M. Pharmacology of macitentan, an orally active tissue-targeting dual endothelin receptor antagonist. The Journal of pharmacology and experimental therapeutics. 2008;327:736-745

42. Sidharta PN, van Giersbergen PL, Halabi A, Dingemanse J. Macitentan: Entry-into-humans study with a new endothelin receptor antagonist. European journal of clinical pharmacology. 2011;67:977-984

43. Sidharta PN, van Giersbergen PL, Dingemanse J. Safety, tolerability, pharmacokinetics, and pharmacodynamics of macitentan, an endothelin receptor antagonist, in an ascending multiple-dose study in healthy subjects. Journal of clinical pharmacology. 2013;53:1131-1138

44. Bruderer S, Hopfgartner G, Seiberling M, Wank J, Sidharta PN, Treiber A, Dingemanse J. Absorption, distribution, metabolism, and excretion of macitentan, a dual endothelin receptor antagonist, in humans. Xenobiotica; the fate of foreign compounds in biological systems. 2012;42:901-910

45. Sidharta PN, Lindegger N, Ulc I, Dingemanse J. Pharmacokinetics of the novel dual endothelin receptor antagonist macitentan in subjects with hepatic or renal impairment. Journal of clinical pharmacology. 2013

46. Dingemanse J, van Giersbergen PL, Patat A, Nilsson PN. Mutual pharmacokinetic interactions between bosentan and lopinavir/ritonavir in healthy participants. Antiviral therapy. 2010;15:157-163

47. Burgess $\mathrm{G}$, Hoogkamer $\mathrm{H}$, Collings $\mathrm{L}$, Dingemanse J. Mutual pharmacokinetic interactions between steady-state bosentan and sildenafil. European journal of clinical pharmacology. 2008;64:43-50 
48. Venitz J, Zack J, Gillies H, Allard M, Regnault J, Dufton C. Clinical pharmacokinetics and drugdrug interactions of endothelin receptor antagonists in pulmonary arterial hypertension. Journal of clinical pharmacology. 2012;52:1784-1805

49. Frampton JE. Ambrisentan. Am J Cardiovasc Drugs. 2011;11:215-226

50. D'Alto M. An update on the use of ambrisentan in pulmonary arterial hypertension. Therapeutic advances in respiratory disease. 2012;6:331-343

51. Atsmon J, Dingemanse J, Shaikevich D, Volokhov I, Sidharta PN. Investigation of the effects of ketoconazole on the pharmacokinetics of macitentan, a novel dual endothelin receptor antagonist, in healthy subjects. Clinical pharmacokinetics. 2013;52:685-692

52. Weiss J, Theile D, Ruppell MA, Speck T, Spalwisz A, Haefeli WE. Interaction profile of macitentan, a new non-selective endothelin-1 receptor antagonist, in vitro. European journal of pharmacology. 2013;701:168-175

53. Bruderer S, Aanismaa P, Homery MC, Hausler S, Landskroner K, Sidharta PN, Treiber A, Dingemanse J. Effect of cyclosporine and rifampin on the pharmacokinetics of macitentan, a tissue-targeting dual endothelin receptor antagonist. The AAPS journal. 2012;14:68-78

54. Chen SJ, Chen YF, Meng QC, Durand J, Dicarlo VS, Oparil S. Endothelin-receptor antagonist bosentan prevents and reverses hypoxic pulmonary hypertension in rats. Journal of applied physiology. 1995;79:2122-2131

55. Clozel M, Hess P, Rey M, Iglarz M, Binkert C, Qiu C. Bosentan, sildenafil, and their combination in the monocrotaline model of pulmonary hypertension in rats. Experimental biology and medicine. 2006;231:967-973

56. Choudhary G, Troncales F, Martin D, Harrington EO, Klinger JR. Bosentan attenuates right ventricular hypertrophy and fibrosis in normobaric hypoxia model of pulmonary hypertension. The Journal of heart and lung transplantation : the official publication of the International Society for Heart Transplantation. 2011;30:827-833

57. Yigitaslan S, Sirmagul B. Relation of bosentan, iloprost, and sildenafil with growth factor levels in monocrotaline-induced pulmonary hypertension. Clinical and experimental hypertension. 2012;34:222-229

58. Clozel M, Roux S. [the pharmacology of endothelin and its antagonist bosentan]. Annales d'endocrinologie. 2000;61:75-79

59. Filep JG, Fournier A, Foldes-Filep E. Acute pro-inflammatory actions of endothelin-1 in the guinea-pig lung: Involvement of eta and etb receptors. Br J Pharmacol. 1995;115:227-236

60. Guimaraes CL, Da-Silva S, Couture R, Rae GA. Mixed endothelin et(a) and et(b) antagonist bosentan inhibits oleic acid-induced lung plasma extravasation in mouse. J Cardiovasc Pharmacol. 2000;36:S371-373

61. Karavolias GK, Georgiadou P, Gkouziouta A, Kariofillis P, Karabela G, Tsiapras D, Sbarouni E, Chaidaroglou A, Degiannis D, Adamopoulos S, Voudris V. Short and long term antiinflammatory effects of bosentan therapy in patients with pulmonary arterial hypertension: Relation to clinical and hemodynamic responses. Expert opinion on therapeutic targets. 2010;14:1283-1289

62. Uhlmann D, Gabel G, Ludwig S, Armann B, Hess J, Pietsch UC, Tannapfel A, Fiedler M, Kratzsch J, Hass J, Witzigmann $\mathrm{H}$. Effects of et(a) receptor antagonism on proinflammatory gene expression and microcirculation following hepatic ischemia/reperfusion. Microcirculation. 2005;12:405-419

63. Gatfield J, Mueller Grandjean C, Sasse T, Clozel M, Nayler O. Slow receptor dissociation kinetics differentiate macitentan from other endothelin receptor antagonists in pulmonary arterial smooth muscle cells. PloS one. 2012;7:e47662

64. Kummer O, Haschke M, Hammann F, Bodmer M, Bruderer S, Regnault Y, Dingemanse J, Krahenbuhl S. Comparison of the dissolution and pharmacokinetic profiles of two galenical formulations of the endothelin receptor antagonist macitentan. European journal of pharmaceutical sciences : official journal of the European Federation for Pharmaceutical Sciences. 2009;38:384-388 
65. Channick RN, Simonneau G, Sitbon O, Robbins IM, Frost A, Tapson VF, Badesch DB, Roux S, Rainisio $M$, Bodin $F$, Rubin L. Effects of the dual endothelin-receptor antagonist bosentan in patients with pulmonary hypertension: A randomised placebo-controlled study. Lancet. 2001;358:1119-1123

66. Rubin L, Badesch DB, Barst RJ, Galie N, Black CM, Keogh A, Pulido T, Frost A, Roux S, Leconte I, Landzberg M, Simonneau G. Bosentan therapy for pulmonary arterial hypertension. The New England journal of medicine. 2002;346:896-903

67. Keogh AM, McNeil KD, Wlodarczyk J, Gabbay E, Williams TJ. Quality of life in pulmonary arterial hypertension: Improvement and maintenance with bosentan. The Journal of heart and lung transplantation : the official publication of the International Society for Heart Transplantation. 2007;26:181-187

68. Galie N, Rubin L, Hoeper M, Jansa P, Al-Hiti H, Meyer G, Chiossi E, Kusic-Pajic A, Simonneau G. Treatment of patients with mildly symptomatic pulmonary arterial hypertension with bosentan (early study): A double-blind, randomised controlled trial. Lancet. 2008;371:20932100

69. Galie N, Beghetti M, Gatzoulis MA, Granton J, Berger RM, Lauer A, Chiossi E, Landzberg M, Bosentan Randomized Trial of Endothelin Antagonist Therapy I. Bosentan therapy in patients with eisenmenger syndrome: A multicenter, double-blind, randomized, placebo-controlled study. Circulation. 2006;114:48-54

70. Sitbon O, Gressin V, Speich R, Macdonald PS, Opravil M, Cooper DA, Fourme T, Humbert M, Delfraissy JF, Simonneau G. Bosentan for the treatment of human immunodeficiency virusassociated pulmonary arterial hypertension. Am J Respir Crit Care Med. 2004;170:1212-1217

71. Savale L, Magnier R, Le Pavec J, Jais X, Montani D, O'Callaghan DS, Humbert M, Dingemanse J, Simonneau G, Sitbon O. Efficacy, safety and pharmacokinetics of bosentan in portopulmonary hypertension. Eur Respir J. 2013;41:96-103

72. Hislop AA, Moledina S, Foster H, Schulze-Neick I, Haworth SG. Long-term efficacy of bosentan in treatment of pulmonary arterial hypertension in children. Eur Respir J. 2011;38:70-77

73. Rosenzweig EB, Ivy DD, Widlitz A, Doran A, Claussen LR, Yung D, Abman SH, Morganti A, Nguyen N, Barst RJ. Effects of long-term bosentan in children with pulmonary arterial hypertension. Journal of the American College of Cardiology. 2005;46:697-704

74. Oudiz RJ, Galie N, Olschewski H, Torres F, Frost A, Ghofrani HA, Badesch DB, McGoon MD, McLaughlin VV, Roecker EB, Harrison BC, Despain D, Dufton C, Rubin L, Group AS. Long-term ambrisentan therapy for the treatment of pulmonary arterial hypertension. Journal of the American College of Cardiology. 2009;54:1971-1981

75. Klinger JR, Oudiz RJ, Spence R, Despain D, Dufton C. Long-term pulmonary hemodynamic effects of ambrisentan in pulmonary arterial hypertension. The American journal of cardiology. 2011;108:302-307

76. Pulido T, Adzerikho I, Channick RN, Delcroix M, Galie N, Ghofrani HA, Jansa P, Jing ZC, Le Brun FO, Mehta S, Mittelholzer CM, Perchenet L, Sastry BK, Sitbon O, Souza R, Torbicki A, Zeng X, Rubin $L$, Simonneau G, Investigators $S$. Macitentan and morbidity and mortality in pulmonary arterial hypertension. The New England journal of medicine. 2013;369:809-818

77. Dupuis J, Hoeper MM. Endothelin receptor antagonists in pulmonary arterial hypertension. Eur Respir J. 2008;31:407-415

78. Affsaps. Thelin ${ }^{\circledast}$ (sitaxentan) : Retrait mondial du marché - communiqué. http://www.afssaps.fr/Infos-de-securite/Communiques-Points-presse/Thelin-R-sitaxentanretrait-mondial-du-marche-Communique. 2010

79. Lavelle A, Sugrue R, Lawler G, Mulligan N, Kelleher B, Murphy DM, Gaine SP. Sitaxentaninduced hepatic failure in two patients with pulmonary arterial hypertension. Eur Respir J. 2009;34:770-771

80. Lee WT, Kirkham N, Johnson MK, Lordan JL, Fisher AJ, Peacock AJ. Sitaxentan-related acute liver failure in a patient with pulmonary arterial hypertension. Eur Respir J. 2011;37:472-474 
81. Hoeper MM. Liver toxicity: The achilles' heel of endothelin receptor antagonist therapy? Eur Respir J. 2009;34:529-530

82. Benedict N, Seybert A, Mathier MA. Evidence-based pharmacologic management of pulmonary arterial hypertension. Clinical therapeutics. 2007;29:2134-2153

83. Fattinger K, Funk C, Pantze M, Weber C, Reichen J, Stieger B, Meier PJ. The endothelin antagonist bosentan inhibits the canalicular bile salt export pump: A potential mechanism for hepatic adverse reactions. Clin Pharmacol Ther. 2001;69:223-231

84. Hartman JC, Brouwer K, Mandagere A, Melvin L, Gorczynski R. Evaluation of the endothelin receptor antagonists ambrisentan, darusentan, bosentan, and sitaxsentan as substrates and inhibitors of hepatobiliary transporters in sandwich-cultured human hepatocytes. Canadian journal of physiology and pharmacology. 2010;88:682-691

85. Markova SM, De Marco T, Bendjilali N, Kobashigawa EA, Mefford J, Sodhi J, Le H, Zhang C, Halladay J, Rettie AE, Khojasteh C, McGlothlin D, Wu AH, Hsueh WC, Witte JS, Schwartz JB, Kroetz DL. Association of cyp2c9*2 with bosentan-induced liver injury. Clinical pharmacology and therapeutics. 2013;94:678-686

86. Roustit M, Fonrose X, Montani D, Girerd B, Stanke-Labesque F, Gonnet N, Humbert M, Cracowski JL. Cyp2c9, slco1b1, slco1b3, and abcb11 polymorphisms in patients with bosentan-induced liver toxicity. Clinical pharmacology and therapeutics. 2014;95:583-585

87. Humbert M, Segal ES, Kiely DG, Carlsen J, Schwierin B, Hoeper MM. Results of european post-marketing surveillance of bosentan in pulmonary hypertension. Eur Respir J. 2007;30:338-344

88. McGoon MD, Frost AE, Oudiz RJ, Badesch DB, Galie N, Olschewski H, McLaughlin VV, Gerber MJ, Dufton C, Despain DJ, Rubin LJ. Ambrisentan therapy in patients with pulmonary arterial hypertension who discontinued bosentan or sitaxsentan due to liver function test abnormalities. Chest. 2009;135:122-129

89. Ben-Yehuda O, Pizzuti D, Brown A, Littman M, Gillies H, Henig N, Peschel T. Long-term hepatic safety of ambrisentan in patients with pulmonary arterial hypertension. Journal of the American College of Cardiology. 2012;60:80-81

90. Bolli MH, Boss C, Binkert C, Buchmann S, Bur D, Hess P, Iglarz M, Meyer S, Rein J, Rey M, Treiber A, Clozel M, Fischli W, Weller T. The discovery of n-[5-(4-bromophenyl)-6-[2-[(5bromo-2-pyrimidinyl)oxy] thoxy]-4-pyrimidinyl]-n'-p ropylsulfamide (macitentan), an orally active, potent dual endothelin receptor antagonist. Journal of medicinal chemistry. 2012;55:7849-7861

91. Nagendran J, Sutendra G, Paterson I, Champion HC, Webster L, Chiu B, Haromy A, Rebeyka $I M$, Ross DB, Michelakis ED. Endothelin axis is upregulated in human and rat right ventricular hypertrophy. Circulation research. 2013;112:347-354

92. Trow TK, Taichman DB. Endothelin receptor blockade in the management of pulmonary arterial hypertension: Selective and dual antagonism. Respir Med. 2009;103:951-962

93. Schirger JA, Chen HH, Jougasaki M, Lisy O, Boerrigter G, Cataliotti A, Burnett JC, Jr. Endothelin a receptor antagonism in experimental congestive heart failure results in augmentation of the renin-angiotensin system and sustained sodium retention. Circulation. 2004;109:249-254

94. Vercauteren M, Strasser D, Vezzali E, Stalder A, Iglarz M, Hess P, Clozel M. Vasopressin is involved in endothelin receptor antagonist-induced fluid retention in rat. Differential effect of selective eta and dual eta/etb receptor antagonists ERS. 2012

95. Maron BA, Waxman AB, Opotowsky AR, Gillies H, Blair C, Aghamohammadzadeh R, Loscalzo $J$, Leopold JA. Effectiveness of spironolactone plus ambrisentan for treatment of pulmonary arterial hypertension (from the [aries] study 1 and 2 trials). The American journal of cardiology. 2013;112:720-725

96. Dingemanse J, Sidharta PN, Maddrey WC, Rubin L, Mickail H. Efficacy, safety and clinical pharmacology of macitentan in comparison to other endothelin receptor antagonists in the treatment of pulmonary arterial hypertension. Expert opinion on drug safety. 2013 
97. Dhillon S, Keating GM. Bosentan: A review of its use in the management of mildly symptomatic pulmonary arterial hypertension. Am J Cardiovasc Drugs. 2009;9:331-350 